\title{
A responsabilidade social universitária no âmbito dos centros locais de aprendizagem da Universidade Aberta de Portugal
}

\author{
Karin Vieira da Silva ${ }^{1}$ \\ Marilei Osinski ${ }^{2}$ \\ Anderson Sasaki Vasques Pacheco ${ }^{3}$
}

\begin{abstract}
RESUMO
A responsabilidade social universitária é um tema recente na gestão universitária e que expande a percepção dos papéis das Instituições de Ensino Superior, discutindo a finalidade de suas ações de ensino, pesquisa e extensão, em conjunto com a transparência de sua gestão com seus stakeholders. Nesse escopo, este trabalho tem como objetivo analisar a efetivação das práticas de responsabilidade social universitária da Universidade Aberta de Portugal, por meio de seus Centros Locais de Aprendizagem. Para o alcance desse objetivo, levantou-se informações de ensino e extensão com os diplomados na universidade por meio de formulários e entrevistas semiestruturadas. Como principais resultados, encontrou-se indicativos de práticas de responsabilidade social corporativa nas ações dos Centro Locais de Aprendizagem nas variáveis estudadas, sendo desenvolvidas atividades de apoio à cultura local, memória histórica local, além de promoção de desenvolvimento regional.
\end{abstract}

Palavras-chave: Responsabilidade Social Universitária; Universidade Aberta de Portugal, Centros Locais de Aprendizagem.

\section{University Social Responsibility within the Local Learning Centers at Open University of Portugal}

\section{ABSTRACT}

The university social responsibility is a recent discussion in university management research, and it expands the perception of the roles of Higher Education Institutions, linking education, research and extension actions, among corporate transparency and accountability in their management practices to their stakeholders. Within this scope, this paper aims to analyse the effectiveness of university social responsibility practices at Portugal Open University, through its Local Learning Centers. To achieve this goal, educational and extension actions information's from university graduates were collected with forms and semi-structured interviews. As main results, it was found corporate social responsibility practices in their activities in the Local Learning Center which supports local culture and historical memory, in addition of regional development promotion with the ex-students.

Keywords: University Social Responsibility; Portugal Open University, Local Learning Centers.

\footnotetext{
${ }^{1}$ Doutora em Sociologia Econômica das Organizações pela Universidade de Lisboa, Professora do Curso de Administração Pública da UDESC Esag. Endereço: Av. Madre Benvenuta, 2007. Itacorubi, Florianópolis/SC Departamento de Administração Pública. CEP: 88.035-901. E-mail: vieira.karin@ gmail.com

${ }^{2}$ Doutoranda em Engenharia e Gestão do Conhecimento pela Universidade Federal de Santa Catarina. R. Eng. Agronômico Andrei Cristian Ferreira, s/n - Trindade, Florianópolis - SC, CEP: 88040-900. E-mail: marileiosinski@gmail.com

${ }^{3}$ Doutor em Sociologia Econômica das Organizações pela Universidade de Lisboa, Professor do Programa de pósgraduação em Gestão Universitária da UFSC. Endereço: R. Eng. Agronômico Andrei Cristian Ferreira, s/n Trindade, Florianópolis - SC, CEP: 88040-900. E-mail: sasaki.anderson @ gmail.com

"Este trabalho foi conduzido durante a bolsa de pesquisa da Coordenação de Aperfeiçoamento de Pessoal de Nível Superior na Universidade de Lisboa. Financiado pela CAPES - do Programa de Bolsa de Estudos para Doutorado Pleno no período de 2013 a 2016."
} 


\section{INTRODUÇÃO}

A Responsabilidade Social é um tema abordado no âmbito organizacional de forma recorrente. Refere-se a ações que vão além de atividades pontuais de assistencialismo/ filantropia, dado à sua relevância não apenas em termos ambientais, mas também culturais. Inicialmente, o conceito de Responsabilidade Social reduzia-se, basicamanete, à Responsabilidade Social Corporativa $(\mathrm{RSC})$ e/ ou à Responsabilidade Social Empresarial (RSE) (BERTO, 2013; VILKE, 2019).

Diante das diversas mudanças sociais causadas pela globalização e pelas novas tecnologias, as universidades passaram a lidar com novas necessidades e desafios, que exigem ações tanto de cunho social, quanto político. Nesse contexto, destaca-se a Responsabilidade Social Universitária (RSU), que atua em quatro dimensões principais: gestão, ensino, pesquisa e extensão (SOUZA, 2016).

A dimensão predominante na literatura é a extensão, citada por La Jara (2002); Vasilescu et al. (2010); Cruz et al. (2010); Berto (2013); Brasileiro, Gonçalves e Targino (2014); Souza (2016); University of Manchester (2019), entre outros. Segundo os referidos autores, a Universidade contribui para a formação nao apenas de estudantes, mas de comunidades socialmente responsáveis.

A extensão pode ocorrer, por exemplo, nos Centros Locais de Aprendizagem (CLAs), que oferecem a infraestrutura para o desenvolvimento das atividades de Responsabilidade Social Universitária. Os Centros Locais de Aprendizagem da Universidade Aberta de Portugal consistem em unidades de atuação presencial das Universidades nos territórios. Alem disso, localizam-se, estrategicamente, em regiões mais suscetíveis à exclusão e são o elo da Universidade com a comunidade e com seus alunos, ressaltando a importância de serem considerados na pesquisa (UAB-PT, 2011).

Nomeados em Portugal como Centros Locais de Aprendizagem, no Brasil são chamados, também, de polos presenciais. Segundo Pinho, Garcia, Esperança e Hartwig (2011), a função destes espaços é oferecer a estrutura adequada para apoiar os alunos, bem como as relações interpessoais. Além disso, servem para abrigar determinadas atividades pedagógicas. Esses ambientes são o resultado de uma parceria entre a Universidade (responsável por desenvolver as atividades pedagógicas) e o governo local (responsável por implementar e manter as estruturas físicas e tecnológicas) (PINHO et al., 2011). 
Desta forma, questiona-se como são realizadas as ações dos CLAs em Portugal, se esses contribuem e promovem ações de responsabilidade social universitária na região que estão inseridos. O objetivo desta pesquisa, portanto, é o de analisar a efetivação das práticas de responsabilidade social universitária da Universidade Aberta de Portugal, por meio de seus Centros Locais de Aprendizagem.

Para a realização da presente pesquisa, foram escolhidos CLAs que se localizam em regiões distantes de grandes centros urbanos e apresentam menores possibilidades em relação a oportunidades de ensino público e de qualidade. No Brasil, assim como em Portugal, as cidades de maior porte abrigam os centros universitários de excelência. Em Portugal, destacase a presença das referidas instituções em Lisboa, Porto e Coimbra, enquanto no Brasil concentram-se nas capitais dos estados da federação. Delimitado o problema, objetivo e objeto e investigação, o próximo caítulo é dedicado aos estudos de responsabilidade social unviersitária.

\section{RESPONSABILIDADE SOCIAL UNIVERSITÁRIA}

A Responsabilidade Social não deve ser reduzida apenas a ações de assistencialismo ou filantropia, mas deve, sim, ser tratada como prioridade social, política e educacional. Ações de filantropia são, geralmente, isoladas, reativas e motivadas por razões humanitárias, enquanto a Responsabilidade Social comumente atua em uma maior amplitude. A Responsabilidade Social é considerada uma nova política de gestão organizacional, que busca minimizar os impactos e os efeitos gerados pela instituição (dentro e fora da mesma), baseia-se em fins éticos, justos e sustentáveis de desenvolvimento social (BERTO, 2013; VILKE, 2019).

Ações de Responsabilidade Social podem ser desenvolvidas tanto por organizações do primeiro como do segundo e do terceiro setor. As universidades, por sua vez, desempenham ações cada vez mais relevantes à sociedade, uma vez que conhecem de perto a comunidade, principalmente por meio de ações de extensão. Assim, seus projetos podem ter respostas mais concretas aos problemas além de respeitar as peculiaridades éticas e culturais de cada região (NUNES; PEREIRA; PINHO, 2017).

Segundo a University of Manchester (2019), a Responsabilidade Social reflete como uma instituição impacta no bem-estar social e econômico da comunidade, por meio de ensino, pesquisa e eventos públicos (extensão). Assim, a Responsabilidade Social é um dos três 
principais objetivos estratégicos da University of Manchester para 2020, juntamente com seus compromissos de pesquisa internacional e de excelência em ensino-aprendizagem.

A extensão universitária é destacada, também, por Cruz et al. (2010) que tratam dos seus benefícios tanto para a Instituição de Ensino Superior (IES) quanto para os participantes e sociedade. Por meio da extensão é possível realizar a transferência de tecnologia social (empoderamento das representações coletivas), através de instrumentos operacionais oriundos da administração. Destaca-se que diversas empresas percebem a importância de práticas de Responsabilidade Social Corporativa, que são consideradas uma estratégia para obter ou manter vantagem competitiva.

No mesmo sentido, a Responsabilidade Social Universitária cresceu em importância em diversos âmbitos acadêmicos, devido a sua contribuição para formar estudantes e comunidades socialmente responsáveis. Atualmente, nota-se uma exigência crescente, por parte da sociedade, para que as universidades prestem contas sobre sua forma de atuação e sobre como capacitam seus estudantes (SILVA, 2015).

O conceito de Responsabilidade Social Universitária é controverso entre os teóricos que estudam o tema, conforme explicam Brasileiro, Gonçalves e Targino (2014). No entanto, há convergência no sentido de priorizar o desenvolvimento humano sustentável, fundamentandose em respeitar os valores e princípios nas ações que são executadas pelas Instituições de Ensino Superior, principalmente no que se refere às atividades de extensão. Nesse contexto, a filosofia de trabalho deve privilegiar uma espécie de contrato ou pacto social entre a universidade e a comunidade específica, a fim de conduzir os esforços para a consolidação do bem comum (seja no âmbito pessoal, social ou institucional).

Além disso, Brasileiro, Gonçalves e Targino (2014) afirmam que da mesma forma como a Responsabilidade Social e a Responsabilidade Social Empresarial são desenvolvidas por políticas, rotinas e programas gerenciais, no contexto universitário a exigência não é distinta, devendo perpassar todos os níveis da organização que as adota, sistematizando o diálogo com os públicos com que mantém relações (stakeholders).

A Responsabilidade Social Universitária refere-se a pensar não apenas nos deveres e nas obrigações da universidade, mas também nas incumbências que são inerentes à natureza institucional de uma IES. Isso envolve a transparência e a ética em suas relações, o respeito à diversidade, as boas condições de trabalho, o respeito às normas democraticamente estabelecidas, entre outras. Trata-se de uma instituição que adota atitudes ética em todas as suas atividades, bem como com todos os atores com os quais interage, tanto interna como 
externamente, não se limitando apenas às "obrigações morais" que são atribuídas pela sociedade aos cidadãos e às organizações sociais (BERTO, 2013).

Complementarmente, Vasilescu et al. (2010); Berto (2013) explicam que uma gestão comprometida com a Responsabilidade Social exige respeitar os princípios do coletivo, a liberdade comunicativa e o exercício corresponsável da vivência em comum. Consequentemente, isso impõe adequações, reconfigurações e redimensionamentos tanto dos processos como das formas de trabalho, uma vez que os projetos de Responsabilidade Social devem ocorrer de modo diversificado, a fim de aliar o ensino, a pesquisa e a extensão por meio de suas estratégias e do envolvimento com a comunidade local.

A principal obrigação da Responsabilidade Social Universitária é propor um modelo social que gere uma sociedade mais justa, menos dividida e mais participativa, onde o ser humano seja um sujeito consciente e livre, sem exclusões. A Responsabilidade Social Universitária refere-se à capacidade que tem a Universidade, como instituição, de difundir e pôr em prática um conjunto de princípios e valores (gerais e específicos), por meio dos processos de gestão, docência, pesquisa e extensão (LA JARA, 2002).

Desta forma, a Responsabilidade Social Corporativa se faz cada vez mais necessária (principalmente no âmbito das instituições federais de ensino superior, nas universidades e nos institutos federais de educação) devido aos aspectos legais e éticos, uma vez que as instituições devem dar algum retorno à sociedade sobre seus gastos públicos. A responsabilidade social universitária ocorre em quatro dimensões: gestão, ensino, pesquisa e extensão (SOUZA, 2016).

La Jara (2002) destaca, dentre as características da Responsabilidade Social Universitária: a) Preservar e criar o capital social do saber e do pensamento mediante a reflexão e a pesquisa interdisciplinar orientada a aportar o desenvolvimento sustentável e melhorar a sociedade como um todo; b) Constituir-se como uma comunidade real de aprendizagem e de criação de conhecimento; c) Formar profissionais altamente qualificados, íntegros, comprometidos com valores que defendem e difundem ativamente; d) Incluir um currículo transversal com uma visão universal da realidade do país; e) Oferecer formação permanente, facilitando o reingresso de egressos à educação superior para atualização e complementação da formação; f) Aberta a mudanças, valorizando e incorporando o conhecimento e experiência do entorno, gerando e mantendo espaços de debate no seio da instituição.

Cruz et al. (2010) esclarecem que uma atuação socialmente responsável é confundida, em muitos casos, com práticas que são, na verdade, assistencialistas ou filantrópicas. Isso ocorre porque algumas organizações se condicionam, apenas, a ações assistencialistas ou filantrópicas 
quando buscam um compromisso com a sociedade. O referido comportamento pode impedir o real crescimento e desenvolvimento de determinado grupo.

No mesmo sentido, La Jara (2002) explica que Responsabilidade Social não é fazer caridade, mas sim fazer uma ação real sobre a sociedade. No caso das universidades, a extensão é uma ferramenta fundamental, utilizada para difundir a cultura e colocar o saber universitário a serviço de toda a sociedade, por exemplo. Além disso, a própria gestão universitária pode ser uma responsabilidade social porque envolve uma quantidade de pessoas e depende de uma enorme quantidade de trabalho.

Propondo um modelo para analisar e estruturar o processo de gestão da Responsabilidade Social Universitária Vallaeys, De La Cruz e Sasia (2009) desenvolvem o seguinte Framework retratado na Figura 1 desta investigação.

Figura 1 - Eixos da Responsabilidade Social Universitária
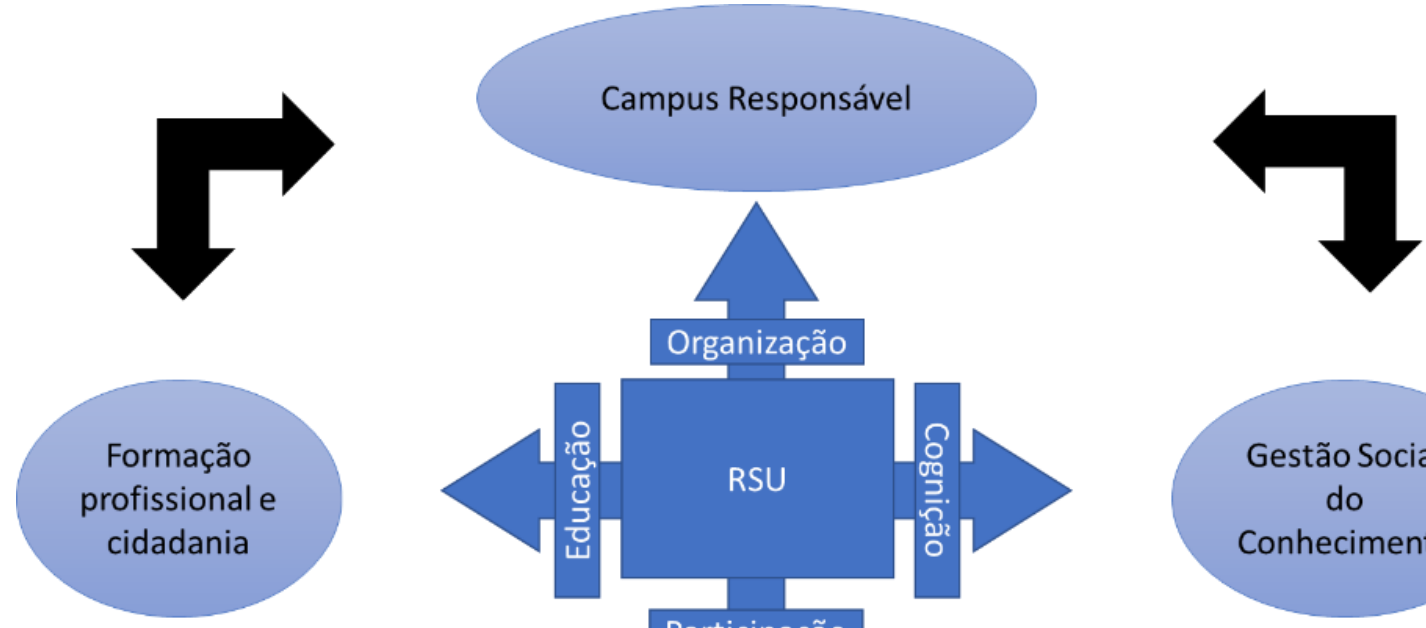

Organização

Formação profissionale cidadania

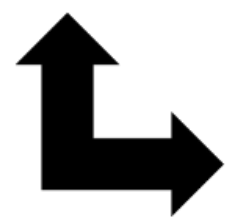

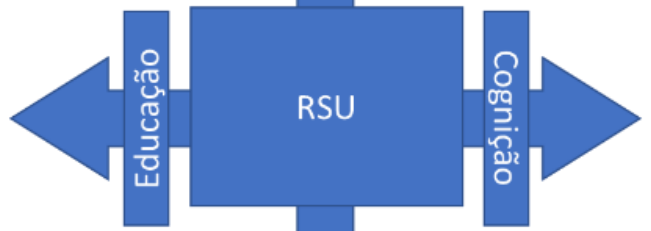

Participação
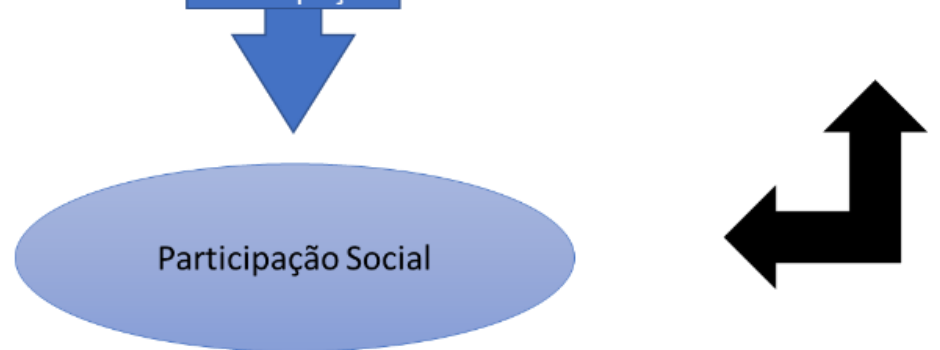

Fonte: Vallaeys, De La Cruz e Sasia (2009)

Baseado em quatro eixos: i) Educação, na formação profissional e cidadania, ii) Organização no Campus Responsável, iii) Cognição/Pesquisa, na gestão social do conhecimento; iv) Participação/Extensão, com a promoção de práticas e ações para a sociedade, o modelo retrata as ações universitárias de forma integralizada, elucidando suas contribuições para a sociedade. 
A grande contribuição deste modelo para o campo da Responsabilidade Social Corporativa está na definição de uma estrutura focada no âmbito das Instituições de Ensino Superior, que rompe com os alicerces dominantes dos modelos de Universidades Europeias e Americanas, sendo um modelo contra a mercantilização do ensino (VALLAEYS, 2014, VIEIRA; BECKHAUSER; PARISOTTO, 2019).

Explicando cada um dos eixos, a Educação, refere-se as práticas de ensino da IES que envolve diversos atores da sociedade como discentes e docentes. Essas práticas vão além do escopo de uma educação funcionalista, refletindo a educação como uma forma de desenvolvimento do território e do indivíduo (VALLAEYS, 2014, VIEIRA; BECKHAUSER; PARISOTTO, 2019).

O segundo eixo, envolve a responsabilização organizacional, tendo principalmente os colaboradores como stakeholders analisados. Entretanto, ressalta-se que, dentro da teoria dos stakeholders (FREEMAN, 1999; FRIEDMAN; MILES, 2002; PHILLIPS, 2003), a responsabilização abrange outros atores interessados. Desta forma, a comunidade também tem interesse quanto aos investimentos organizacionais, sobretudo quanto a transparência organizacional (FILGUEIRAS, 2011, GOMES et al., 2016).

Com relação ao terceiro eixo, da pesquisa, essa "é considerada socialmente responsável, não como um compromisso para o futuro, mas como uma obrigação para o presente", sendo capaz recuperar o sujeito, além de promover a reflexão de seu território (VIEIRA; BECKHAUSER; PARISOTTO, 2019). Como colocado por Freire (2014, p.27) "O conhecimento, pelo contrário, exige uma presença curiosa do sujeito em face do mundo. Requer uma ação transformadora sobre a realidade."

Por fim, o quarto eixo está relacionado com as ações de responsabilidade social na extensão universitária. Conforme Carbonari e Ferreira (2007) a interação entre universidade e sociedade fazem parte de uma nova cultura organizacional em que parcerias entre empresas, organizações da sociedade civil e poder público, poderão dar vazão as necessidades das comunidades em seu entorno.

Ressalta-se que, nesta investigação, os elementos selecionados para a análise dos aspectos de Responsabilidade Social Universitária se encontram no i) Eixo de Educação e iv) participação/extensão, conforme será explicado de forma mais aprofundada no próximo capítulo. 


\section{METODOLOGIA}

No presente estudo utilizou-se uma abordagem de natureza mista, integrando as orientações quantitativa e qualitativa. Embora sejam métodos diferentes de pesquisa, eles não são excludentes e se constituem em uma estratégia de validação de informações empíricas, por meio de diferentes lentes (VÍCTORA; KNAUTH; HASSEN, 2000).

O objeto de estudo é a Universidade Aberta de Portugal, especificamente, os Centros Locais de Aprendizagem. Esses Centros são originários de um projeto iniciado em 2007, com o objetivo de dar suporte logístico e instrumental aos acadêmicos, em especial, na realização das avaliações presenciais, atividades de aprendizagem ao longo da vida, ações de promoção da literacia digital, de competências, em âmbito acadêmico, profissional, cultural e cívico, e de intervenções educativas e culturais, com base nas dinâmicas locais (UAB-PT, 2011).

Eles são criados e mantidos por meio de parcerias entre a Universidade Aberta e os governos das localidades onde estão inseridos, e estão estrategicamente localizados em regiões mais suscetíveis à exclusão, especialmente, educacional (UAB-PT, 2011).

Portanto, os CLAs escolhidos para este estudo estão localizados em regiões distantes dos grandes centros urbanos, que apresentam menores possibilidades no que se refere às oportunidades de ensino público e de qualidade, nomeadamente, nas cidades de Grândola, Porto de Mós, Ponte de Lima e Ribeira Grande (esta última na Região Autônoma dos Açores).

A pesquisa compreende, portanto, os alunos diplomados em Gestão, entre os anos de 2010 e 2014, que estavam relacionados aos Centros Locais pesquisados. Durante este período a Universidade Aberta de Portugal diplomou 451 alunos no curso de gestão. Com o recorte dos Centros Locais alunos que se encontram fora dos grandes centros urbanos, foram excluídos os alunos que residiam nas regiões metropolitanas de Porto e Lisboa e, também, os alunos residentes em outros países, visto que o interesse é focado nas comunidades locais. A exclusão destas regiões delimitou a amostra da pesquisa em 200 alunos.

A técnica utilizada, no âmbito quantitativo da pesquisa, foi o formulário. Com o intuito obter respostas aos formulários foram realizados quatro contatos intervalados via e-mail, contato telefônico e envio de mensagens via telefone e Facebook. A taxa total foi de 42,5\% (85 respondentes). As variáveis analisadas buscavam compreender a percepção dos alunos sobre i) a importância do centro local de aprendizagem para a região - Eixo Educacional e a ii) integração entre o CLA e comunidade local - Eixo da Participação Social (VALLAEYS; DE LA CRUZ; SASIA, 2009). 
Como suporte para a análise dos dados quantitativos, recolhidos mediante a aplicação de questionários, foi utilizado o software SPSS, versão 22. O tratamento dos dados estatísticos recorreu à uma análise descritiva, apresentada por meio de gráficos e tabelas. A aplicação dos questionários aconteceu no período de janeiro a março de 2016.

Com o intuito de aprofundar a compreensão da percepção dos alunos sobre essas variáveis, foram realizadas entrevistas semiestruturadas com dezenove diplomados, localizados em diferentes regiões do país: três do Norte, seis dos Açores, dois do Alentejo, dois do Algarve, dois da Madeira e quatro do Centro. Ao total foram entrevistados quarenta e três diplomados; e quatro coordenadores, responsáveis pelos seguintes centros locais de aprendizagem: Grândola, Porto de Mós, Ponte de Lima e Ribeira Grande.

A análise dos dados se deu por meio da análise do conteúdo das entrevistas. Os coordenadores estão identificados na análise pela sigla $C$ " $n$ "” e os alunos pela sigla $A$ " $n$ ", conforme se verá na seção a seguir. Destaca-se, por fim, que os dados da pesquisa de campo integram um estudo realizada no âmbito de trabalho de doutorado, financiado pela CAPES.

\section{RESPONSABILIDADE SOCIAL NA UNIVERSIDADE ABERTA DE PORTUGAL}

A presente pesquisa se norteou por duas questões principais: uma relacionada à percepção dos alunos sobre a importância dos Centros Locais de Aprendizagem para a sua região e a outra versa sobre a integração entre CLAs e comunidade local. Sobre a importância dos centros locais de aprendizagem (gráfico 1) 66,2\% dos pesquisados afirmam que eles são fundamentais $(28,4 \%)$ ou bastante importantes $(37,8 \%)$ para a região.

Os testemunhos dos alunos permitiram compreender alguns aspectos evidenciados pelos questionários. A primeira questão é que uma parcela dos entrevistados não teve grande contato com os Centros Locais de Aprendizagem durante a licenciatura.

Como se verifica nas respostas dos formulários, cerca de $23 \%$ não souberam opinar sobre o papel do CLA. Isto porque, conforme destaca um dos coordenadores, os centros locais de aprendizagem são iniciativas relativamente recentes: "A Universidade Aberta há cerca de oito anos teve essa visão pioneira de criar um polo presencial em territórios que tinham uma certa exclusão em níveis de oferta de ensino superior" (C7). 
Gráfico 1 - Importância do centro local de aprendizagem para a região - UAb/Portugal para os diplomados.

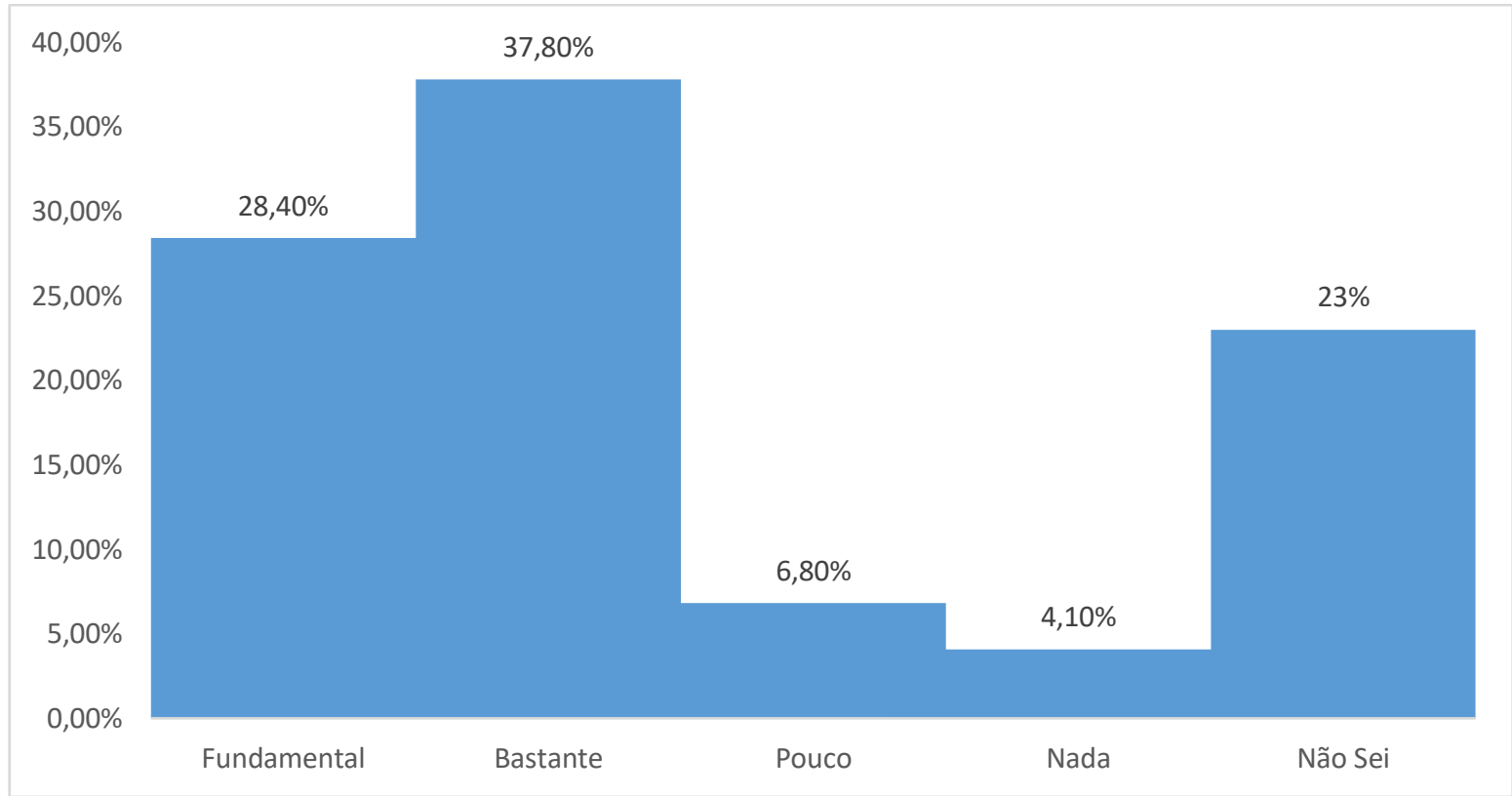

Fonte: Elaborado pelos autores.

* Ressalta-se que a utilização da escala com essas nomenclaturas teve como base sugestões de demais pesquisadores portugueses.

Portanto, alguns alunos somente tiveram contato com o CLA no final da licenciatura e, alguns, nem o tiveram, pois, até então, havia somente os centros de exames, que cumpriam a função exclusiva de receber os alunos nas épocas de avaliação. Tal informação pode explicar a significativa parcela de pesquisados que afirmou não saber opinar sobre a atuação dos centros locais de aprendizagem e dá alguns indicativos sobre os motivos que levaram uma parcela significativa dos pesquisados (23\%) a dizer não saber responder a questão sobre a importância do centro local de aprendizagem para a região (23\%) (vide Gráfico 1).

Dentre os alunos que reforçaram a importância dos CLAs para as suas regiões, os principais aspectos relatados estão relacionados com o fomento da educação e os impactos ao nível econômico que poderia proporcionar, conforme ilustra o relato a seguir: "Talvez seja um instrumento para alavancar as experiências das pessoas, portanto, seria, de uma forma positiva, uma mais valia para a cidade. Por que seria uma mais valia? Naturalmente, no sentido de incentivar essas pessoas a estudar, aprender e evoluir (A38)".

O entrevistado A38 relata as suas vivências com pessoas que tiveram as suas condições de vida impactadas pelo curso realizado na Universidade Aberta: “Eu conheço pessoas que fizeram o curso de gestão e fizeram um upgrade na carreira. (...) Aumenta o ordenado, aumenta o poder de compra, portanto, consegue um nível econômico e social mais confortável, até quem não viajava antes, agora pode viajar, já pode alargar as suas relações”. Outros testemunhos dão conta de que os Centros Locais podem ajudar a valorizar os municípios em que se encontram, dando maior visibilidade a eles: "Acaba 
por ser importante porque essas cidades menores também precisam de ser divulgadas e, ao ter lá um Centro, acaba por chamar a atenção, acaba por chamar mais pessoas bocadinho” (A37).

Assim, os relatos dão indicativos sobre a melhoria das condições econômicas e laborais dos diplomados. Vale ressaltar que, de acordo com Demo (1994, p. 31), "trabalhar/produzir e participar definiriam as oportunidades históricas das pessoas e sociedades, desde que almejem ao projeto próprio de desenvolvimento". O autor argumenta que a auto-sustentação é um dos pilares para o processo de emancipação cidadã, uma vez que considera a participação sem auto-sustentação constitui-se em uma farsa, dado que está permeada por relações de dependência.

Com relação a análise dos aspectos de Responsabilidade Social Universitária os relatos das entrevistas dão indicativos para o papel educacional proposto no modelo de Vallaeys, De La Cruz e Sasia (2009). O ensino ao proporcionar uma educação voltada ao desenvolvimento social do ser e que impacta no acesso a recursos necessários para a vida decente, elucida-se como uma prática de responsabilidade social universitária relevante para o desenvolvimento local (VIEIRA; BECKHAUSER; PARISOTTO, 2019).

Sobre as indicações a respeito das contribuições dos CLAs para as localidades que os abrigam é interessante resgatar a ideia de Correia e Pereira (2006, p.71) sobre os spillovers do conhecimento, que se configuram como o "derramamento" do conhecimento adquirido por um indivíduo no contexto em que ele está inserido, trazendo contribuições que, no caso aqui estudado, possuem potencial para alterar positivamente os arranjos produtivos e econômicos das regiões, especialmente, a longo prazo.

$\mathrm{Na}$ visão dos coordenadores, uma das principais contribuições da Universidade Aberta e dos CLAs é ampliar o acesso à educação nos territórios mais suscetíveis à exclusão ao nível de ensino superior: "Somos uma vila mais rural, portanto, acho que a Universidade Aberta veio permitir um maior desenvolvimento acadêmico e profissional (...). O Centro veio permitir um maior desenvolvimento social e cultural para além da formação, e é um meio de divulgação cultural e social" (C10). "A grande mais valia foi a possibilidade de centralizarmos a oferta de ensino superior nesses territórios e, ainda por cima, envolver e facilitar todas as vertentes das suas vidas, acadêmica, familiar, profissional" (C7).

Portanto, os relatos dão indicativos de que a presença dos Centros Locais de Aprendizagem nos territórios estudados possui um importante papel na ampliação das possibilidades de acesso ao ensino superior, em localidades onde ele é restrito. Lück (2008) destaca que a EaD pode proporcionar à indivíduos de lugares remotos, o acesso à educação, uma vez que não limita geograficamente a atuação das instituições de ensino. Isso vai ao encontro do que, segundo Guri-Rosenblit (2009, p.109), é um dos objetivos da educação a distância desde a sua origem, "atingir grupos especiais que, por uma variedade de razões, não puderam participar de encontros presenciais, uma escola ou um campus convencional, e fornecer-lhes informação ou educação".

No que tange a segunda variável, a integração CLA e a comunidade local, verificou-se que 48,6\% dos inquiridos consideram que os CLAs possuem uma relação com a comunidade local; para 
$23 \%$ essa relação é pouca $(14,9 \%)$ ou nula $(8,1 \%)$ e uma parcela significativa $(28,4 \%)$ não soube responder.

Com relação às possibilidades que a comunidade tem para usufruir da estrutura física dos CLAs, $48 \%$ afirmaram que há muita abertura para isso, 17,6\% disseram que as possibilidades são poucas $(9,5 \%)$ ou nulas $(8,1 \%)$. Outros $33,8 \%$ não souberam responder à questão. Quanto à promoção de eventos sociais ou culturais, $33,8 \%$ disseram que eles são promovidos com muita frequência, já 32,4\% afirmaram que os eventos ocorrem com pouca $(24,3 \%)$ ou nenhuma $(8,1 \%)$ frequência. Os restantes $33,8 \%$ disseram não saber sobre o assunto.

A percepção dos alunos sobre a realização de ações de integração entre CLA e comunidade local revelou que, para 39,2\%, essas ações são realizadas com muita frequência, já $27,1 \%$ disseram que as possibilidades são poucas $(14,9 \%)$ ou nulas $(12,2 \%)$. Outros 33,8\% não souberam responder à questão.

Sobre a realização de ações de integração entre comunidade local e alunos os resultados demonstraram que somente $27,1 \%$ disseram que tais ações são feitas com muita frequência, enquanto $35,2 \%$ atestam que ações dessa natureza são pouco $(17,6 \%)$ ou nada $(17,6 \%)$ realizadas. Novamente uma parcela significativa $(35,1 \%)$ disse não saber (ver Gráfico 2 ).

No que tange a atuação dos Centros Locais de Aprendizagem com os alunos e as comunidades que os abrigam foi possível verificar por meio de duas fontes que, nos CLAs pesquisados, há a promoção de eventos destinados para além dos alunos, que incluem a sociedade civil.

Gráfico 2 - Integração CLA e comunidade local - UAb/Portugal.

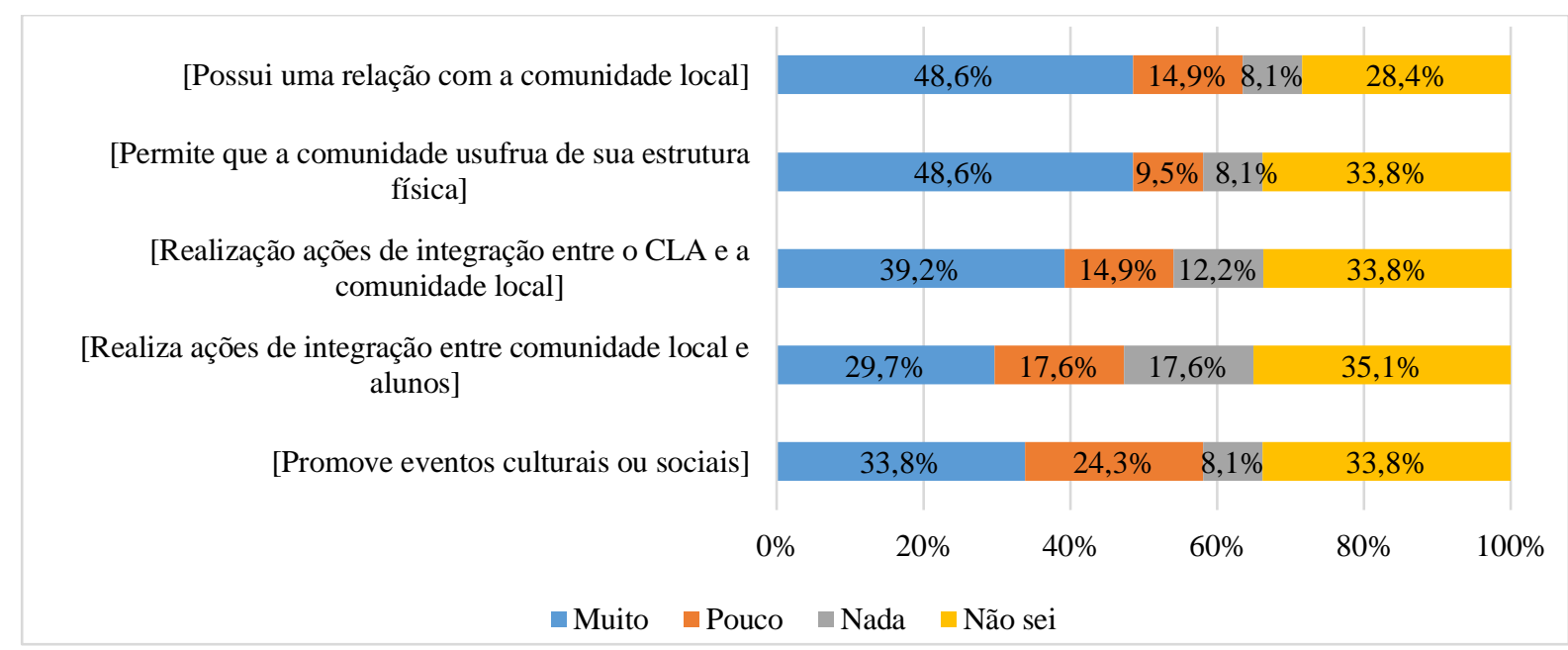

Fonte: Elaborado pelos autores.

Os relatos dos coordenadores revelaram a realização, por parte dos CLAs, de diferentes iniciativas, desde atividades culturais envolvendo música, teatro, poesia, literatura, dança, até a promoção de eventos em que se debatem questões como igualdade de gênero, história/cultura local e assuntos acadêmicos: "Organizei, em conjunto com a câmara municipal, uma ação 
sobre histórias da resistência no feminino, que ligou a parte da história ligada à resistência, com a parte da igualdade de gênero. Fomos procurar mulheres do município para valorizar a memória local, que estivessem estado presas na altura do Estado Novo e para dar voz a esses tipos de mulheres. (...) Aqui, neste exemplo, fica outro pormenor patente, que, apesar do centro local de aprendizagem pertencer à Aberta, o nosso objetivo não é convidar só pessoas da Aberta, ou seja, é sempre estabelecer parcerias com outros a nível quer de organismos $e$ instituições locais, quer nacionais, e convidarmos, também, os centros de outras universidades para estabelecer estas pontes entre instituições e organismos (A7).

Outro relato, demostra a preocupação de integrar a história do território e a cultura local nas atividades realizadas pelos CLAs: "Tivemos um (evento) agora sobre um rio que corta a cidade, temos que estar atentos a essas questões locais, como disse há bocado, não só pensar se temos oradores com essas temáticas, mas percebermos o que interessa a nível local, fazer cá. Na conferência sobre o rio, abordamos historicamente a importância desse recurso natural e como é visto hoje em dia, essas questões ligadas à água, ao rio, essas questões ao nível local e juntamos com o meio ambiente" (A10).

No discurso dos coordenadores foi possível perceber que, de fato, há uma grande preocupação com o papel social da Universidade Aberta e a importância da integração entre os centros locais de aprendizagem com os territórios em que estão abrigados: "Eu acho que a academia, para além do contributo do ensino superior em si, deve estar na linha da frente das soluções do terreno (...) nós como instituição de ensino nos perguntarmos como podemos alavancar isso, como podemos fazer parte da solução (...) acredito que a solução da universidade nos territórios é ter cada vez mais a preocupação de aumentar e cuidar do capital social, trabalhar com as instituições locais de uma forma próxima, valorizar os seus produtos" (C9). "Os CLAs têm uma atividade muito importante no desenvolvimento de atividades socioculturais e educativas, procuramos desenvolver uma série de iniciativas, normalmente em parceria com os agentes do território, com a câmara municipal, com associações, com redes sociais, para responder quer à falta e à pouca oferta de iniciativas nesses territórios $(C 7)$.

Verifica-se, portanto, que os eventos desenvolvidos, vão ao encontro da percepção extensionista de responsabilidade social universitária analisada por Vieira, Beckhauser e Parisotto (2019, p.12) "como função institucional" que atua de forma abrangente e que considere a difusão de conhecimento, assim como a cultura do território.

Embora os dados coletados indiquem uma preocupação e efetiva atuação dos Centros Locais de Aprendizagem na realização de eventos destinados aos seus alunos e à comunidade 
local, uma das grandes dificuldades encontradas é fomentar a participação da sociedade civil, e, principalmente, dos estudantes, que encontram dificuldade em conciliar os eventos com os demais compromissos laborais e familiares.

No caso da integração das comunidades nos eventos dos CLAs, as dificuldades também aparecem e estão relacionadas, por vezes, com a configuração sócio demográfica das localidades: "Temos que enfrentar a dificuldade de estarmos em territórios, às vezes, com pouco população, com população idosa (...). No início isso foi um grande obstáculo (...) mas, graças a Deus, conseguimos formas de lidar com essa realidade (C7).

Sendo os Centros Locais de Aprendizagem o elo entre a Universidade e as comunidades locais, entende-se que as suas atividades devem transcender os limites do apoio pedagógico aos alunos e envolver a comunidade como um todo, mediante ações de integração e de atividades socioculturais. Assim, as comunidades têm a oportunidade de usufruir diretamente dos benefícios das Universidades. O fato de os Centros Locais estudados demonstrarem essa preocupação e desenvolverem ações efetivas para tanto, sinaliza a possibilidade concreta de integração entre a Universidade e o território, mesmo na modalidade a distância.

É importante ressaltar que, conforme salienta Zottis et. al. (2008), a Universidade deve estar atenta ao seu papel social, preocupando-se, portanto, em dar contrapartidas às comunidades que a abrigam e sustentam. Nesse sentido, na percepção dos pesquisados, a Universidade Aberta de Portugal contribui, por meio de seus Centros Locais de Aprendizagem, para o aumento do acesso ao ensino superior, desenvolvimento profissional dos estudantes, integração do conhecimento e experiência de seus entornos para o desenvolvimento de atividades que vão além da ensino formal, com atividades de extensão, e ganho de visibilidade de regiões interioranas de Portugal, o que vai ao encontro de elementos importantes da responsabilidade social universitária, na perspectiva de Jara (2002) e na estrutura de responsabilidade social de Vallaeys, De la Cruz e Sasia (2009)

\section{CONSIDERAÇÕES FINAIS}

As instituições universitárias possuem um relevante papel no desenvolvimento das comunidades, em especial, daquelas que às abrigam, ao proporcionar, não apenas o desenvolvimento de habilidades profissionais e acesso ao ensino superior, mas, também, no desempenho de uma ampla função social, ao externalizar seus benefícios para a sociedade em geral (ZOTTIS et. al. 2008). 
No caso da educação à distância, essa questão ganha uma roupagem diferente, uma vez que os estudantes não estão tão estreitamente vinculados ao espaço físico da Universidade, comparativamente ao estudantes do ensino presencial, assim como, a Universidade possui uma presença diferente nos territórios, por meio, por exemplo, dos Centros Locais de Aprendizagem, no caso de Portugal.

No entanto, isso não às exime de práticas de responsabilidade social, ou seja, de contribuir efetivamente para o desenvolvimento humano sustentável, atentando para os princípios e valores de suas ações, especialmente no que tange as atividades de extensão e educação (BRASILEIRO; GONÇALVES; TARGINO, 2014).

Nesse sentido, entende-se que a Universidade Aberta de Portugal, por meio de seus Centros Locais de Aprendizagem estudados, embora enfrente algumas dificuldades, efetiva práticas de responsabilidade social universitária, ao preocupar-se em interagir com o território onde está inserida, promovendo iniciativas que vão ao encontro da realidade local, abrangendo variadas temáticas, que envolvem questões sociais, históricas, culturais, acadêmicas, entre outras.

Além disso, os CLAs, nos territórios, materializam uma possibilidade de acesso ao ensino superior em localidades carentes de acesso próximo e facilitado a ele, o que contribui, potencialmente, para o desenvolvimento das pessoas e, consequentemente, do território. Vale ressaltar que, um dos objetivos da responsabilidade social universitária é contribuir para uma sociedade mais justa, participativa e inclusiva, e que o acesso a educação é um elemento fundamental nesse processo (LA JARA, 2002).

Destaca-se, também, a presença de uma externalidade positiva da presença dos centros locais de aprendizagem nas localidades, relacionada à maior visibilidade dessas regiões, uma vez que os relatos dão indicativos de que os alunos passam a ter a possibilidade de conhecer os locais onde os CLAs estão inseridos e acabam, por vezes, interagindo com o território e suas dinâmicas.

Por fim, destaca-se que a educação é um aspecto determinante no desenvolvimento das comunidades, em especial, em uma sociedade em que o conhecimento é fator-chave para melhoria das condições econômicas e sociais da população (SOBRAL, 2000).

Nesse sentido, é imprescindível que as Universidades desempenhem o seu "papel social, devolvendo constantemente para a sociedade o resultado do conhecimento obtido, financiado pelos impostos de toda a população, contribuindo para o desenvolvimento sustentável" (ZOTTIS et. al, 2008, p. 36). Para tanto, atividades que integrem comunidade e Universidade 
são fundamentais, dado que se constituem em uma possibilidade efetiva de devolver à sociedade o saber que a Universidade constrói (SIMIONATTO, 2014). Nesse contexto, a pesquisa aqui apresentada encontrou indicativos de que a Universidade Aberta de Portugal possui uma atuação relevante, em termos de responsabilidade social, perante as comunidades em que estão inseridos os seus Centros Locais de Aprendizagem.

Todavia, é interessante o desenvolvimento de pesquisas que incluam novas variáveis do modelo proposto por Vallaeys, De la Cruz e Sasia (2009), que aprofundem as estudadas nesse artigo, ou, ainda, estudem mais Centros Locais de Aprendizagem, de modo a compreender melhor esse cenário e suas dinâmicas e variações.

\section{REFERÊNCIAS}

BERTO, A. B. F. Responsabilidade social universitária: princípios e valores em prol do desenvolvimento da comunidade. Perspectivas online: ciências humanas e sociais aplicadas, Campos dos Goytacazes, v. 6, n. 3, p. 16-25, 2013.

BRASILEIRO, F. S.; GONÇALVES; E. F.; TARGINO, M. G. Novas perspectivas para a Responsabilidade social universitária: reflexão sobre o projeto de educação popular e apoio à saúde da família - Universidade Federal da Paraíba. Revista FSA, Teresina, v. 11, n. 3, art. 8, p. 208-229, jul./set. 2014.

CARBONARI, M. E. E.; PEREIRA, A. C. A extensão universitária no Brasil, do assistencialismo à sustentabilidade. Revista de Educação, [S. l.], v. 10, n. 10, p. 23-28, 2007.

CORREIA, I. M.; PEREIRA, O. P. Spillovers do conhecimento e desenvolvimento regional: evidência de Portugal. Revista Portuguesa de Estudos Regionais, 13, 67-82, 2006.

CRUZ, B. de P. A.; MELO, W. S.; MALAFAIA, F. C. B.; TENÓRIO, F. G. Extensão Universitária e Responsabilidade Social: 20 anos de Experiência de uma Instituição de Ensino Superior. In: Anais do XXXIV Encontro da ANPAD - ENANPAD 2010 - Encontro da Associação Nacional de Pósgraduação e Pesquisa em Administração. Rio de Janeiro: 2010.

DEMO, P. Política social, educação e cidadania. Papirus Editora, 1994.

FILGUEIRAS, F. Além da transparência: accountability e política da publicidade. Lua nova: revista de cultura e política, n. 84, p. 323-364, 2011.

FREEMAN, R. E. Divergent stakeholder theory. Academy of management review, v. 24, n. 2, p. 233-236, 1999.

FREIRE, P. Extensão ou comunicação? São Paulo: Editora Paz e Terra, 2014.

FRIEDMAN, A. L.; MILES, S. Developing stakeholder theory. Journal of management studies, v. 39, n. 1, p. 1-21, 2002.

GOMES, D. E. et al. Panorama de estudos acerca da transparência nas universidades públicas: uma contribuição para a gestão universitária. In: XVI CIGU 2016, Peru. Anais do XVI CIGU. Peru: INPEAU/UFSC, 2016. 
GURI-ROSENBLIT, S. Distance Education in the Digital Age: Common Misconceptions and Challenging Tasks. Journal Of Distance Education, Canada, 23 (2), 105-122, 2009.

LA JARA, Mónica Jiménez de. La universidad construye país. 2002. Disponível em:

〈http://www.bibliotecavirtual.info/wp-content/uploads/2012/01/la_universidad_construye_pais.pdf $>$. Acesso em: nov. 2019.

LÜCK, E. H. Educação a distância: contrapondo críticas, tecendo argumentos. Revista Educação, (31) 3, 258-267, 2008.

NUNES, E. B. L. de L. P.; PEREIRA, I. C. A.; PINHO, M. J. de. A responsabilidade social universitária e a avaliação institucional: reflexões iniciais. Avaliação: Revista da Avaliação da Educação Superior (Campinas), v. 22, n. 1, p. 165-177, 2017. Disponível em: https://doi.org/10.1590/s1414-40772017000100009

PHILLIPS, R. Stakeholder theory and organizational ethics. Oakland: Berrett-Koehler Publishers, 2003.

PINHO, D. S., GARCIA, N. M., ESPERANÇA, J. A.; HARTWIG, S. C. Contribuições do núcleo de apoio aos polos. In: VIII Congresso Brasileiro de Ensino Superior a Distância. Ouro Preto, Brasil, 2011.

SILVA, I. A. S. Responsabilidade social universitária, qualidade e pertinência social: desafios à gestão. Diálogo, Canoas, n. 29, p. 09-28, ago. 2015.

SIMIONATTO, I. Intelectualidade, política e produção do conhecimento: desafios ao Serviço Social. Serviço Social \& Sociedade, 117, 7-21, 2014.

SOBRAL, F. S. F. Educação para a competitividade ou para cidadania social. São Paulo em Perspectiva, 14(1), 3-11, 2000.

SOUZA, P. C. A contribuição dos projetos de extensão de cunho social para a formação cidadã do aluno do Instituto Federal de Santa Catarina à luz da Responsabilidade social universitária. 2016. Dissertação (Mestrado) - Programa de Pós-Graduação em Administração Universitária, Universidade Federal de Santa Catarina, Florianópolis, 2016.

THE UNIVERSITY OF MANCHESTER. Social responsibility. 2019. Disponível em: <https://www.manchester.ac.uk/discover/social-responsibility/>. Acesso em: 10 nov. 2019.

UAB-PT. (2011). Centros Locais de Aprendizagem. Disponível em: http://www.uab.pt/web/guest/organizacao/servicos/servicos-desconcentrados/cla . Acesso em outubro/2014.

VALLAEYS, F. La responsabilidad social universitaria: un nuevo modelo universitario contra la mercantilización. Revista Iberoamericana de Educación Superior, v. 2014, p. 13, 2014.

VALLAEYS, F.; DE LA CRUZ, C.; SASIA, P. M. Responsabilidad social universitaria: Manual de primeros pasos. 1. ed. New York: BID, 2009.

VASILESCU, R.; BARNA, C.; EPURE, M.a; BAICU, C. Developing university social responsibility: A model for the challenges of the new civil society. Procedia - Social and Behavioral Sciences, v. 2, n. 2, p. 4177-4182, 2010. 
VÍCTORA, C. G., KNAUTH, D. R., HASSEN, M. Metodologias Qualitativa e Quantitativa. In: Pesquisa Qualitativa em Saúde: uma introdução ao tema. Porto Alegre: Tomo Editorial, 2000.

VIEIRA, C. D. C. N.; BECKHAUSER, S. P. R.; PARISOTTO, I. R. dos S. Responsabilidade Social universitária: um estudo sobre seu significado para os representantes dos grupos de interesse de uma universidade. Revista de Negócios, v. 23, n. 4, p. 7, 2019. Disponível em:

https://doi.org/10.7867/1980-4431.2018v23n4p7-24

VILKE, R. Towards holistic understanding of socially responsible provision of public goods: conceptual foundations, Social Responsibility Journal, v. 15, n. 1, p. 47-60, 2019.

ZOTTIS, G. A. H., Cunha, L. L., Krebs, L. F., Algeri, S.; Flores, R. Z. Violência e desenvolvimento sustentável: o papel da Universidade. Saúde e Sociedade, 17(3), 33-41, 2008. 